\title{
Comparison of intravenous Magnesium Sulphate with intrathecal Magnesium Sulphate for post- operative analgesia in orthopaedic patients undergoing extracapsular hip fracture surgery
}

\author{
Arvind Kumar ${ }^{1}$, Usha Kumari Chaudhary ${ }^{2}$, Dinesh Kansal ${ }^{1}$, Shelly Rana ${ }^{2}$, \\ Vipin Sharma ${ }^{3}$, Parbeen Kumar ${ }^{1}$
}

\author{
${ }^{1}$ Department of Pharmacology, \\ ${ }^{2}$ Department of Anaesthesia, \\ ${ }^{3}$ Department of Orthopaedics, \\ Dr. Rajendra Prasad Govt. \\ Medical College, Tanda, \\ Kangra, Himachal Pradesh, \\ India
}

Received: 02 November 2016

Accepted: 29 November 2016

*Correspondence to:
Dr. Arvind Kumar,
Email:
arvindchaudhary116@gmail.co
m

Copyright: (C) the author(s), publisher and licensee Medip Academy. This is an openaccess article distributed under the terms of the Creative Commons Attribution NonCommercial License, which permits unrestricted noncommercial use, distribution, and reproduction in any medium, provided the original work is properly cited.

\begin{abstract}
Background: Magnesium sulphate $\left(\mathrm{MgSO}_{4}\right) \mathrm{N}$ methyl D aspartate receptor antagonist has the potential to be an ideal adjuvant for postoperative analgesia via intrathecal or intravenous route. The aim of the study was, we compared the efficacy of two routes of $\mathrm{MgSO}_{4}$ (Intravenous vs intrathecal) as an adjuvant to bupivacaine in subarachnoid block (SAB).

Methods: Ninety, American Society of Anesthesiologists physical status 1 or 2 patients, aged 20-60 years, scheduled for hip surgeries under SAB were recruited in department of Anaesthesia and Dept. of Orthopaedics. Patients in group $1(\mathrm{n}=29)$ received intrathecal $0.5 \%(\mathrm{H})$ bupivacaine $15 \mathrm{mg}$ with $0.1 \mathrm{ml}$ of normal saline and $250 \mathrm{ml} 0.9 \%$ normal saline intravenous 30 minutes before giving SAB. Group $2(\mathrm{n}=30)$ patients received intrathecal $0.5 \%$ bupivacaine $15 \mathrm{mg}$ with $0.1 \mathrm{ml}$ of normal saline and $50 \mathrm{mg} / \mathrm{kg}$ of magnesium sulphate in 250 $\mathrm{ml}$ normal saline intravenous 30minutes before giving SAB. In Group $3(n=30)$ patients received intrathecal $0.5 \%(\mathrm{H})$ bupivacaine $15 \mathrm{mg}$ with $50 \mathrm{mg}(0.1 \mathrm{ml})$ magnesium sulphate and $250 \mathrm{ml} 0.9 \%$ normal saline intravenous 30 minutes before giving SAB. They were evaluated for block characteristics, visual analogue scale at various time intervals up to 24 hours and total rescue analgesic and duration of postoperative analgesia were noted.

Results: Intravenous magnesium sulphate had maximum pain free interval, lower pain scores, longer sensory and motor blockade and less requirement of rescue analgesia as compared to the patients in intrathecal group or control group $(\mathrm{P}<0.05)$.

Conclusions: Intravenous magnesium sulphate was more effective as compared to intrathecal route with regards to the pain scores and in providing postoperative analgesia.
\end{abstract}

Keywords: Adjuvants, Anesthesia, Analgesia, Magnesium Sulfate, Pain, Postoperative

\section{INTRODUCTION}

Magnesium sulphate has been reported to be effective in perioperative pain treatment by virtue of its antagonist effect on NMDA receptors. ${ }^{1}$ Although magnesium is not a primary analgesic in itself, it enhances the analgesic actions of local anaesthetics as an adjuvant. Antinociceptive effects of magnesium appear to be relevant not only to chronic pain, but it also determines, in part, the duration and intensity of postoperative pain. ${ }^{2,3}$
Numerous clinical investigations have demonstrated that $\mathrm{Mg}$ infusion during general anaesthesia reduces anaesthetic requirement and postoperative analgesic consumption, whereas other studies suggested that perioperative IV (intravenous) $\mathrm{Mg}$ administration had little effect on postoperative pain. ${ }^{4,5}$

It is likely that intrathecal magnesium sulphate potentiates spinal anaesthesia by a localized action on spinal nociceptive pathways, explaining the absence of central side-effects after systemic administration of large 
doses of magnesium. ${ }^{6}$ As intrathecal magnesium alone has been shown to induce sensory and motor block. ${ }^{7}$ It is expected that magnesium might potentiate the spinal block due to a synergistic interaction between NMDA antagonists and LA (local anaesthetic). The efficacy and safety of intrathecal magnesium sulphate is reported in rats and human in earlier studies. ${ }^{8}$ Till date single study has compared the effect of the intravenous and intrathecal magnesium on the postoperative pain and suggested that co-administration of intravenous $\mathrm{Mg}$ sulphate or intrathecal $\mathrm{Mg}$ given to patients undergoing spinal anaesthesia for total hip arthroplasty could improve pain control for the first $24 \mathrm{~h}$ after surgery. ${ }^{9}$ While there was no significant difference between the two modalities as regard pain scores, however, IV magnesium led to relative hypotension and decreased blood loss. Further studies are still needed to verify these results.

Therefore, we planned a study to compare the analgesic efficacy of intravenous magnesium sulphate versus intrathecal magnesium as an adjuvant to bupivacaine, in patients scheduled for extracapsular hip surgeries under spinal anaesthesia.

\section{METHODS}

After approval by Institutional Ethics Committee (HFWH-DRPGMC/Ethics/2014/39) and CTRI registration (CTRI/2015/06/005923), a prospective, randomized controlled, double blind study was carried out on 90 patients of both sexes in the age group of 20-60 years over a period of 18 months. Patients were ASA I-2, scheduled for lower limb surgeries under subarachnoid block. Patients refusal for spinal anaesthesia, having bleeding diathesis, uncontrolled and labile hypertension, allergy to any of the study drugs and BMI $>40 \mathrm{~kg} / \mathrm{m}^{2}$ were exclusion criteria.

The patients were randomly allocated to one of the three groups by random number chart. Randomization was done by computer generated randomized number table. Random number was enclosed in a sealed opaque envelope and was opened by one of investigator to know the study drug/combination to be administered, only after shifting of patient inside operation theatre. Observer who collected postoperative data was blinded to the test drug/combination administered through intravenous and intrathecal route.

The anaesthetic procedure was explained to the patients enrolled for the study and thereafter written consent was taken. All patients were given ringer lactate at the rate of $10 \mathrm{ml} / \mathrm{kg} /$ hour before the procedure for preloading. Standard monitoring of ECG, NIBP and pulse oximetry was attached. All patients in three groups received $250 \mathrm{ml}$ of drug solution 30 minutes before subarachnoid block as per allocation. After antiseptic skin preparation and sterile draping, lumbar puncture was done at the level of $\mathrm{L}_{3}-\mathrm{L}_{4}$ vertebra with $26 \mathrm{G}$ Quincke' spinal needle in lateral position and $3.1 \mathrm{ml}$ of study drug solution was given after confirming the free flow of CSF.

Three groups received the pre mixed coded solutions per randomization. Group $1 \quad(\mathrm{n}=30)$ patients received intrathecal $0.5 \%$ heavy bupivacaine $15 \mathrm{mg}$ (Anawin *Heavy, Neon Laboratories limited, Palghar, M.S.) with $0.1 \mathrm{ml}$ of normal saline and $250 \mathrm{ml} 0.9 \%$ normal saline intravenous 30 minutes before giving subarachnoid block. Group $2(n=30)$ patients received intrathecal $0.5 \%$ heavy bupivacaine $15 \mathrm{mg}(3 \mathrm{ml})$ with $0.1 \mathrm{ml}$ of normal saline and $50 \mathrm{mg} / \mathrm{kg}$ of magnesium sulphate (Magneon, $50 \% \mathrm{v} / \mathrm{w}$, total volume $2 \mathrm{ml}$ by Neon Laboratories limited, Mumbai)in $250 \mathrm{ml}$ normal saline intravenous 30minutes before giving subarachnoid block. In Group $3(\mathrm{n}=30)$ patients received intrathecal $0.5 \%(\mathrm{H})$ bupivacaine $15 \mathrm{mg}(3 \mathrm{ml})$ with $50 \mathrm{mg}(0.1 \mathrm{ml})$ magnesium sulphate and $250 \mathrm{ml} 0.9 \%$ normal saline intravenous 30 minutes before giving subarachnoid block.

After placing the patient in supine position, the sensory level was assessed by pinprick sensation using a blunt $25 \mathrm{G}$ needle along the midclavicular line bilaterally at 3 , $6,9,12,15,20,25$ and $30 \mathrm{~min}$. and then every $15 \mathrm{~min}$. The time to reach the sensory level up to T10 dermatome and maximum sensory level, the time for two segment regression and to $\mathrm{S} 1$ segment regression recorded. The motor level was assessed according to modified Bromage scale to know the time to reach Bromage level 1 and the time to Bromage 5 regression.

All patients were monitored intraoperatively for systolic, diastolic, mean blood pressure, heart rate, oxygen saturation and respiratory rate every 1 minute for first 10 minute and then every $5 \mathrm{~min}$ for half an hour and then every 15 minute till the end of surgery in operating room and also in recovery room. Any hypotension (SBP $<90$ $\mathrm{mmHg}$ ) episode was treated with injection mephentermine $6 \mathrm{mg}$ bolus and episodes of bradycardia (HR <40 beats/min) were treated with intravenous atropine $0.02 \mathrm{mg} / \mathrm{kg}$. Postoperatively patients were observed for vitals and pain in the recovery room and then in the postsurgical ward for 24 hrs.

Severity of pain was measured using a 10 point visual analogue scale (VAS) at hourly interval for next 6 hours after subarachnoid block and then at $8^{\text {th }}, 10^{\text {th }}, 12^{\text {th }}, 15^{\text {th }}$, $18^{\text {th }}$ and $24^{\text {th }}$ hour. The postoperative rescue analgesia was provided by inj. diclofenac sodium $75 \mathrm{mg}$ IM (intramuscular) (VAS >3). Block characteristics and duration of analgesia were the primary outcome, whereas number of rescue analgesics required and intraoperative haemodynamic parameters was the secondary outcomes.

Data was collected and entered in MS Excel 2007. Parametric data like heart rate, BP were compared and analysed by Kruskal-Wallis test whereas non-parametric data such as VAS, rescue analgesics were analysed by Mann-Whitney $U$ test and Chi-square test. The Bonferroni correction was used to correct for multiple 
testing at different time points. Time for first rescue analgesic medication was analysed using survival analysis and Cox-regression analysis. A value of $\mathrm{p}<0.05$ was considered significant.

After approval by Institutional Ethics Committee (HFWH-DRPGMC/Ethics/2014/39) and CTRI registration (CTRI/2015/06/005923), a prospective, randomized controlled, double blind study was carried out on 90 patients of both sexes in the age group of 20-60 years over a period of 18 months. Patients were ASA I-2, scheduled for lower limb surgeries under subarachnoid block. Patients refusal for spinal anaesthesia, having bleeding diathesis, uncontrolled and labile hypertension, allergy to any of the study drugs and BMI $>40 \mathrm{~kg} / \mathrm{m}^{2}$ were exclusion criteria. The patients were randomly allocated to one of the three groups by random number chart. Randomization was done by computer generated randomized number table. Random number was enclosed in a sealed opaque envelope and was opened by one of investigator to know the study drug/combination to be administered, only after shifting of patient inside operation theatre. Observer who collected postoperative data was blinded to the test drug/combination administered through intravenous and intrathecal route.

The anaesthetic procedure was explained to the patients enrolled for the study and thereafter written consent was taken. All patients were given ringer lactate at the rate of $10 \mathrm{ml} / \mathrm{kg} /$ hour before the procedure for preloading. Standard monitoring of ECG, NIBP and pulse oximetry was attached. All patients in three groups received $250 \mathrm{ml}$ of drug solution 30 minutes before subarachnoid block as per allocation. After antiseptic skin preparation and sterile draping, lumbar puncture was done at the level of $\mathrm{L}_{3}-\mathrm{L}_{4}$ vertebra with $26 \mathrm{G}$ Quincke' spinal needle in lateral position and $3.1 \mathrm{ml}$ of study drug solution was given after confirming the free flow of CSF.

Three groups received the pre mixed coded solutions per randomization. Group $1 \quad(n=30)$ Patients received intrathecal $0.5 \%$ heavy bupivacaine $15 \mathrm{mg}$ (Anawin *Heavy, Neon Laboratories limited, Palghar, M.S.) with $0.1 \mathrm{ml}$ of normal saline and $250 \mathrm{ml} 0.9 \%$ normal saline intravenous 30 minutes before giving subarachnoid block. Group $2(n=30)$ patients received intrathecal $0.5 \%$ heavy bupivacaine $15 \mathrm{mg}(3 \mathrm{ml})$ with $0.1 \mathrm{ml}$ of normal saline and $50 \mathrm{mg} / \mathrm{kg}$ of magnesium sulphate (Magneon, $50 \% \mathrm{v} / \mathrm{w}$, total volume $2 \mathrm{ml}$ by Neon Laboratories limited, Mumbai)in $250 \mathrm{ml}$ normal saline intravenous 30minutes before giving subarachnoid block. InGroup $3 \quad(n=30)$ patients received intrathecal $0.5 \%(\mathrm{H})$ bupivacaine $15 \mathrm{mg}$ (3ml) with $50 \mathrm{mg}(0.1 \mathrm{ml})$ magnesium sulphate and $250 \mathrm{ml}$ $0.9 \%$ normal saline intravenous 30 minutes before giving subarachnoid block.

After placing the patient in supine position, the sensory level was assessed by pinprick sensation using a blunt $25 \mathrm{G}$ needle along the midclavicular line bilaterally at 3 , $6,9,12,15,20,25$ and $30 \mathrm{~min}$. and then every $15 \mathrm{~min}$.
The time to reach the sensory level up to T10 dermatome and maximum sensory level, the time for two segment regression and to $\mathrm{S} 1$ segment regression recorded. The motor level was assessed according to modified Bromage scale to know the time to reach Bromage level 1 and the time to Bromage 5 regression.

All patients were monitored intraoperatively for systolic, diastolic, mean blood pressure, heart rate, oxygen saturation and respiratory rate every 1 minute for first 10 minute and then every $5 \mathrm{~min}$ for half an hour and then every 15 minute till the end of surgery in operating room and also in recovery room. Any hypotension (SBP $<90$ $\mathrm{mmHg}$ ) episode was treated with injection mephentermine $6 \mathrm{mg}$ bolus and episodes of bradycardia $(\mathrm{HR}<40$ beats/min) were treated with intravenous atropine $0.02 \mathrm{mg} / \mathrm{kg}$. Postoperatively patients were observed for vitals and pain in the recovery room and then in the postsurgical ward for $24 \mathrm{hrs}$.

Severity of pain was measured using a 10 point visual analogue scale (VAS) at hourly interval for next 6 hours after subarachnoid block and then at $8^{\text {th }}, 10^{\text {th }}, 12^{\text {th }}, 15^{\text {th }}$, $18^{\text {th }}$ and $24^{\text {th }}$ hour. The postoperative rescue analgesia was provided by inj. diclofenac sodium $75 \mathrm{mg}$ IM (intramuscular) (VAS >3). Block characteristics and duration of analgesia were the primary outcome, whereas number of rescue analgesics required and intraoperative haemodynamic parameters was the secondary outcomes.

Data was collected and entered in MS Excel 2007. Parametric data like heart rate, BP were compared and analysed by Kruskal-Wallis test whereas non-parametric data such as VAS, rescue analgesics were analysed by Mann-Whitney $U$ test and Chi-square test. The Bonferroni correction was used to correct for multiple testing at different time points. Time for first rescue analgesic medication was analysed using survival analysis and Cox-regression analysis. A value of $\mathrm{p}<0.05$ was considered significant.

\section{RESULTS}

After approval of institution ethics committee and CTRI registration, ninety patients were included in the study and randomly divided into three groups (Figure 1). Patients in the three groups were comparable with regard to age, BMI, ASA status and duration of surgery (Table 1).

The time taken to reach T10 segment was comparable in three groups 1,2 and $3(2.551 \pm 1.055,2.900 \pm 1.46$ and 3.000 $\pm 1.856:: \mathrm{P}=0.488$ ) minutes respectively (Figure 2). The time to achieve peak sensory level was (mean \pm SD: $4.320 \pm 1.266,2.900 \pm 1.464$ and $3.000 \pm 1.856) \mathrm{min}$. in group 1,2 and 3 respectively $(\mathrm{P}=0.092)$. Similarly the time taken to reach Bromage 1 was also comparable in all the three groups (mean \pm SD: $3.286 \pm 1.019,3.416 \pm 1.414$ and 3.900 $\pm 2.550:: \mathrm{P}=0.384) \mathrm{min}$. in groups 1,2 and 3 (Figure 2). 


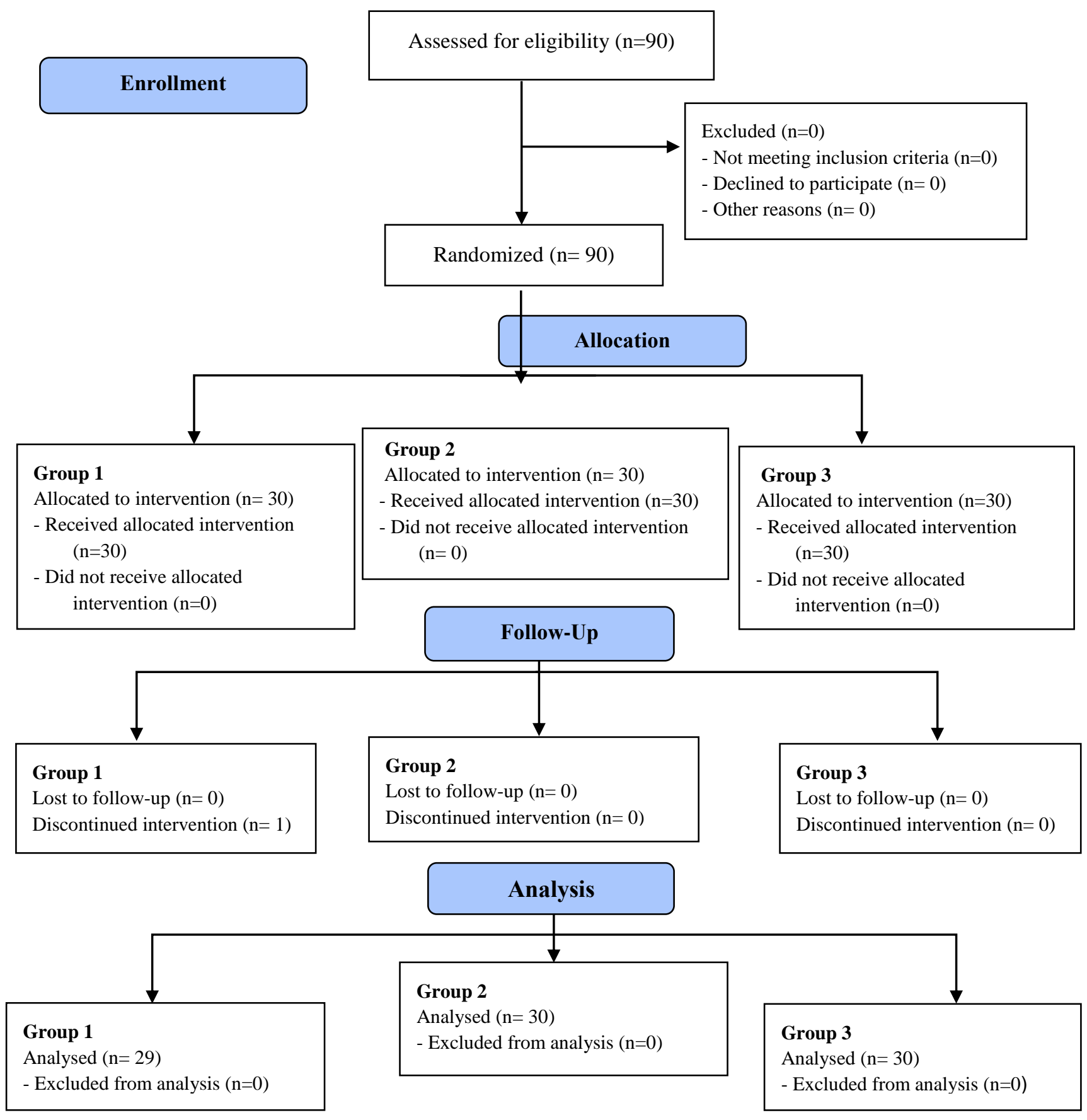

Figure 1: Patients recruited and analyzed in three groups.

Table 1: Demographic data.

\begin{tabular}{|llll|} 
Variable & $\begin{array}{l}\text { Group 1 control group } \\
(\mathbf{n}=\mathbf{2 9})\end{array}$ & $\begin{array}{l}\text { Group 2 IV group } \\
(\mathbf{n}=\mathbf{3 0})\end{array}$ & $\begin{array}{c}\text { Group 3 IT group } \\
(\mathbf{n}=\mathbf{3 0})\end{array}$ \\
\hline Age $($ Years $)$ & $52.66 \pm 8.776$ & $51.13 \pm 9.413$ & $49.57 \pm 11.057$ \\
\hline Weight $(\mathrm{kg})$ & $61.93 \pm 6.491$ & $58.23 \pm 6.663$ & $57.10 \pm 7.810$ \\
\hline Height $(\mathrm{cm})$ & $156.21 \pm 6.383$ & $154.20 \pm 7.989$ & $156.90 \pm 6.294$ \\
\hline BMI $\left(\mathrm{Kg} / \mathrm{m}^{2}\right)$ & $25.157 \pm 2.445$ & $24.390 \pm 2.983$ & $23.530 \pm 3.185$ \\
\hline ASA Status $(\mathrm{I} / \mathrm{II})$ & $29 / 0$ & $28 / 2$ & $28 / 2$ \\
\hline Duration of surgery (min.) & $105.17 \pm 32.26$ & $94.72 \pm 19.94$ & $103.31 \pm 31.43$ \\
\hline
\end{tabular}

Value expressed as mean \pm SD

Expressed as number of patients in each group and analyzed by Chi square test. 


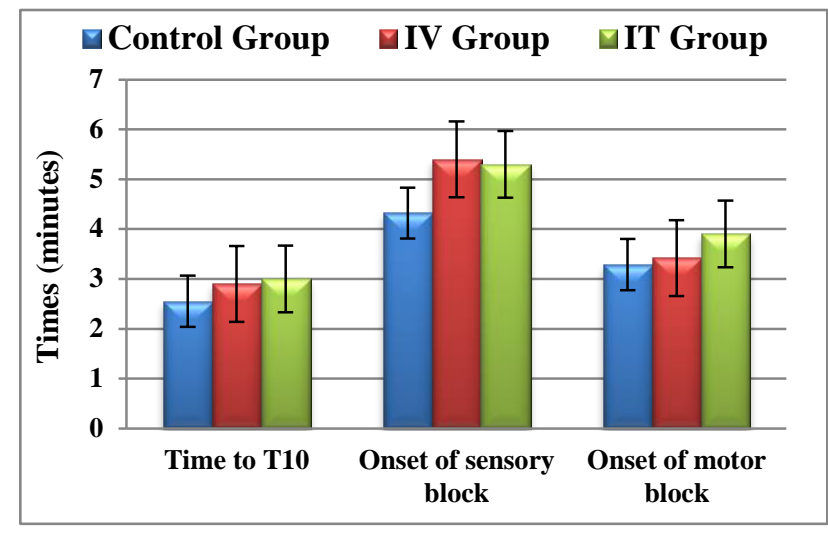

Figure 2: Comparison of onset of motor and sensory block.

The total duration of sensory block defined as regression to $\mathrm{S} 1$ segment was $(104.89 \pm 27.01,135.13 \pm 36.79$ and $129.4 \pm 34.80:: \mathrm{P}=0.001$, group1 and $2: \mathrm{P}=0.002$ and group $1 \& 3: \mathrm{P}=0.01)$ minutes in group 1,2 and 3 respectively. The duration of motor block taken as time to Bromage 5 regression was $(174.06 \pm 66.85,208.466 \pm 54.735$ and 176.300 $\pm 45.841: \mathrm{P}=0.035$, group 1 and $2:: \mathrm{P}=0.03$ and group 2 and $3:: \mathrm{P}=0.02$ ) minutes in groups 1,2 and 3 respectively (Figure 3 ).

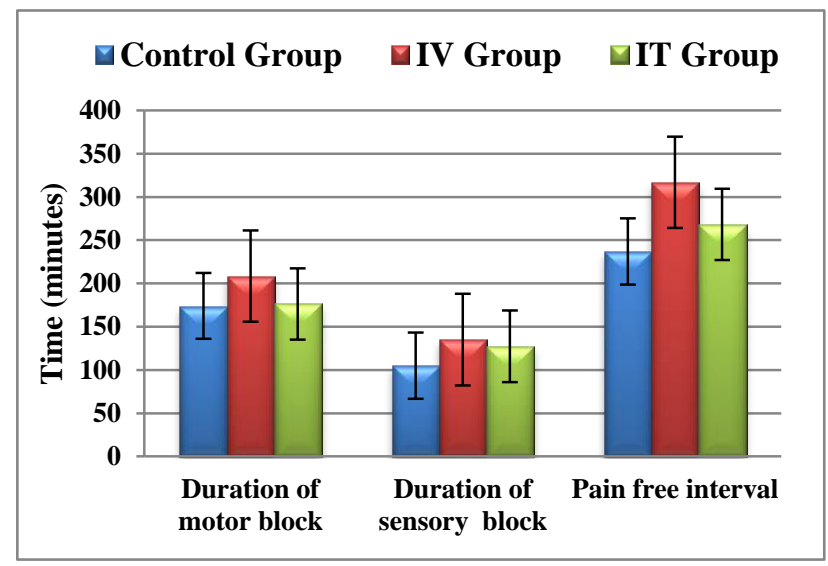

Figure 3: Comparison of block characteristics.

Pain free interval was defined as time interval between administration of test drug and the first rescue analgesic was $(237.07 \pm 89.52, \quad 317 \pm 116.2$ and $268.28 \pm 104.93$ : $\mathrm{P}=0.008$, group $1,2: \mathrm{P}=0.04)$ minutes in group 1,2 and 3 respectively (Figure 3 ). There was significant decrease in the visual analogue score (VAS) in intrathecal and intravenous group as compared to control group (Figure 4). The pain score was less in intravenous group at all intervals except $4^{\text {th }} \mathrm{hr}, 12^{\text {th }} \mathrm{hr}, 15^{\text {th }} \mathrm{hr}$ and $24^{\text {th }} \mathrm{hr}$ postoperatively as compared to the control group. The pain score was also less at $1^{\text {st }}, 2^{\text {nd }}$ and $8^{\text {th }} \mathrm{hr}$ in intravenous group as compared to the intrathecal group $(\mathrm{P}=0.04)$. The pain scores were less in intrathecal group as compared to the control group at $1^{\text {st }}, 5^{\text {th }}, 6^{\text {th }}, 10^{\text {th }}, 15^{\text {th }}$ and $18^{\text {th }}$ hour $(\mathrm{P}=0.002)$. The rescue analgesic requirement was significantly less in intravenous group and intrathecal group as compared to control group $(\mathrm{P}=0.012)$. The total rescue analgesic requirement was 147.41 \pm 24.40 , $122.50 \pm 36.76$ and $134.48 \pm 30.91:: \mathrm{P}=0.012$, groups 1 and 2: $\mathrm{P}=0.009$ ) $\mathrm{mg}$ in groups 1,2 and 3 respectively (Figure $5)$.

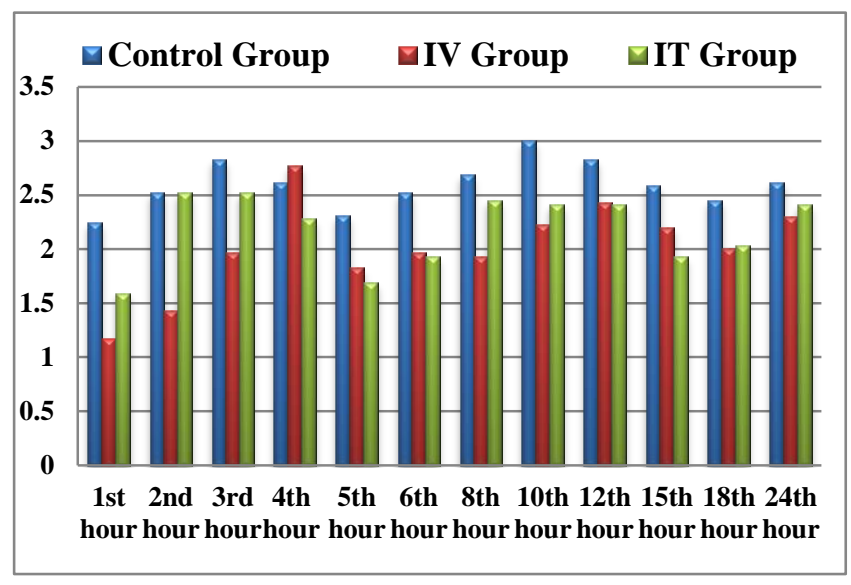

Figure 4: Comparison of postoperative pain scores.

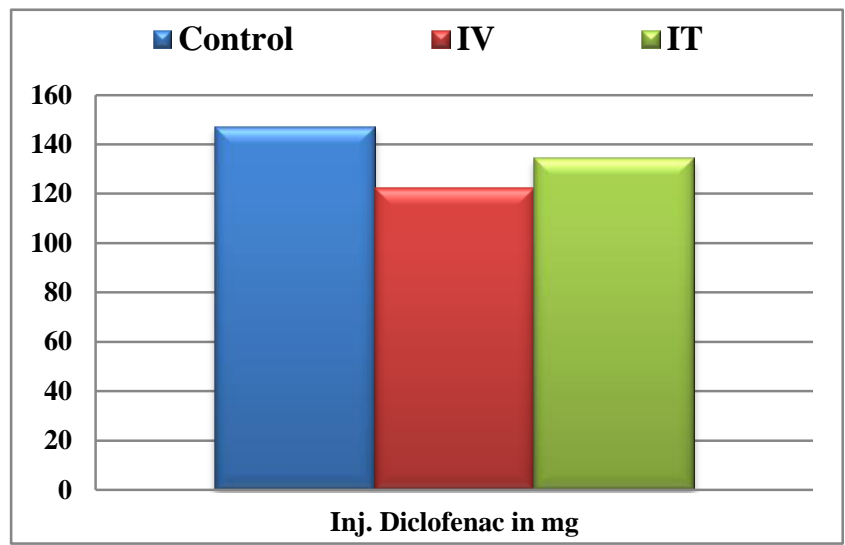

Figure 5: Requirement of rescue analgesia.

Intraoperative heamodynamics including heart rate, diastolic, mean and systolic blood pressure and peripheral oxygen saturation were comparable in three groups at all study interval time periods and did not require any intervention.

\section{DISCUSSION}

Recent years have witnessed increased interest in perioperative pain management with the aim enhancing dynamic restoration of functions especially after orthopaedic surgery. Good postoperative analgesia is associated with improved outcome in terms of reduction in opioid consumption, early mobility and decreased hospital stay.

Magnesium have been very widely used as pre-emptive analgesia, so we therefore planned a study to compare the effects of magnesium sulphate as a pre-emptive analgesic either through intravenous route given preoperatively 
prior to subarachnoid block or as an adjuvant to intrathecal bupivacaine. Hypothesis was that magnesium sulphate prolongs the duration of motor and sensory block and also prolongs the time to first analgesia when given via either of the two routes as compared to the control.

We have used magnesium sulphate in the single bolus dose of $50 \mathrm{mg} / \mathrm{kg}$ given over a period of 30 minutes prior to subarachnoid block in accordance to study done by Kiran $S$ and colleagues. ${ }^{10}$ They concluded that preoperative magnesium sulphate infusion decreases postoperative pain and requirement of rescue analgesia. Similarily, in the meta analysis byAlbrecht and colleagues it is suggested that a single bolus administration of magnesium sulphate between 40 and 50 $\mathrm{mg} / \mathrm{kg}$ reduces postoperative morphine consumption. ${ }^{11}$

The dose of intrathecal magnesium used in this study was based on data from Buvendraan et al, where $50 \mathrm{mg}$ of spinal magnesium sulphate potentiated fentanyl antinociception. ${ }^{12}$ Intrathecal magnesium sulphate potentiates spinal anaesthesia by a localized action on spinal nociceptive pathways, explaining the absence of central side-effects after systemic administration of large doses of magnesium. ${ }^{13}$ As intrathecal magnesium alone has been shown to induce sensory and motor block, ${ }^{7}$ it is presumed that magnesium might potentiate the spinal block due to a synergistic interaction between local anaesthetics and NMDA antagonists.

In our study the onset time for peak sensory block (T6) was prolonged in IV group $(5.400 \pm 2.40 \mathrm{~min}$.) as compared to intrathecal group $(5.300 \pm 2.306 \mathrm{~min}$.$) and$ control group $(4.32 \pm 1.266 \mathrm{~min}$.) $(\mathrm{P}=0.143)$. Time to Bromage 1 was also more in intrathecal group $(3.90 \pm 2.55 \mathrm{~min})$ as compared to IV group (3.416 \pm 1.414 min.) as well as control group $(3.286 \pm 1.019 \mathrm{~min})$ $(\mathrm{p}=0.781)$. These results are in accordance with the results by Samir et al, wherein the onset of sensory (T10) block was $(4.78 \pm 0.78 \mathrm{~min}$. $4.97 \pm 0.74 \mathrm{~min}, 5.0 \pm 0.69 \mathrm{~min}$; $\mathrm{p}=0.549)$ in control, intrathecal and intravenous groups respectively. ${ }^{14}$ Similarily the onset of motor block was (7.68 $\pm 0.70 \mathrm{~min}, 6.72 \pm 2.97 \mathrm{~min}, 7.34 \pm 0.80 \mathrm{~min}$; $\mathrm{p}=0.128$ ) in control, intrathecal and intravenous groups respectively. The increased time taken in their study might be because of different end point taken as onset of motor block (Bromage 3) in comparison to Bromage 1 in our study. Secondly they have combined fentanyl to intrathecal LA and magnesium.

We observed that the administration of magnesium via either route prolongs the duration of motor and sensory blockade. The duration of sensory block was increased in intravenous group $(135.655 \pm 37.333 \mathrm{~min}$.) as well as in intrathecal group (129.379 $\pm 33.662 \mathrm{~min}$.) as compared to the control group $(104.896 \pm 27.011 \mathrm{~min}: \mathrm{P}=0.001)$. The duration of motor block was $(173.14 \pm 67.89 \mathrm{~min}$, 209.78 $\pm 56.42 \mathrm{~min}$. and $175.10 \pm 47.23 \mathrm{~min}: \mathrm{P}=0.033)$ in control, IV magnesium and intrathecal magnesium groups respectively.

Similar results were observed by Samir et $\mathrm{al}^{14}$ who found that the sensory blockade was maximum in intravenous group (303.7 $\pm 21.77 \mathrm{~min}$.) as compared to intrathecal group (299.7 $\pm 18.31 \mathrm{~min}$.) and control group (227.1 $\pm 16.26:: \quad \mathrm{P}=0.001)$, but this difference was not statistically significant between intravenous and intrathecal group. Motor block was (198.1 $244.03 \mathrm{~min}$.) in intravenous group as compared to the intrathecal group (200.4 $\pm 11.81 \mathrm{~min}$.) and control group (193.88 $\pm 21.41 \mathrm{~min}$.) $(\mathrm{p}=0.66)$. The discrepancy in the motor duration in the IV and IT magnesium may be because of addition of intrathecal fentanyl.

However in the study by Kumar et al, the authors observed that duration of sensory block $(237.10 \pm 37.19$, 242.80 $\pm 23.88:: \mathrm{P}=0.48) \mathrm{min}$ and motor block $(287.87 \pm 31.61, \quad 270.40 \pm 24.87:: \quad \mathrm{P}=0.39)$ minutes in magnesium and control groups were comparable. ${ }^{15}$ The timing of magnesium sulphate infusion might be the contributing factor as it was started just prior to spinal block in this study, whereas in our study the single bolus infusion was started thirty minutes prior to subarachnoid block.

In the present study patients in intravenous group were pain free for longest period $(317 \pm 116.21 \mathrm{~min})$ as compared to intrathecal $(268.28 \pm 104.93 \mathrm{~min})$ and control $(237.07 \pm 89.52 \mathrm{~min})$ groups. The rescue analgesic requirement was also least in the intravenous group $(122.50 \pm 36.76 \mathrm{mg})$ as compared to intrathecal $(134.48 \pm 30.9 \mathrm{mg})$ and control (147.41 $\pm 24.4 \mathrm{mg}:$ : $\mathrm{P}=0.012$ ). The pain free period in the study by Samir EM et al was maximum in the intravenous and intrathecal group as compared to the control group. ${ }^{14}$ The difference between the intrathecal group and intravenous group was also statistically significant. This was in accordance with our study, however the duration of the pain free period was less in this study as compared to our study which can be due to the use of lower dose of bupivacaine in their study $(2.4-3.0 \mathrm{mg})$. The requirement of rescue analgesia was maximum in the control group as compared to the intravenous group and intrathecal group in the form of injection meperidine. This difference between the intravenous group and the intrathecal group was not statistically significant.

Similarily, Kumar $\mathrm{M}$ and colleagues studied sixty patients who underwent spinal anaesthesia with bupivacaine and received infusion magnesium sulphate prior to subarachnoid block and concluded that the maximum pain free period was more in the group receiving magnesium infusion $(333.91 \pm 202.41)$ min. as compared to control group $(232.68 \pm 140.62)$ minutes $(\mathrm{P}=0.04){ }^{15}$ 
Analgesic consumption and pain scores at rest have not been related with central sensitization but it has to do with wind-up phenomenon and hyperalgesia. ${ }^{16}$ Lower concentrations of magnesium may interact with N-type calcium channel activity that mediates pain signalling. $\mathrm{N}$ type calcium channels are highly concentrated in the synaptic terminals they make in the dorsal horn of the spinal cord (laminae I and II). ${ }^{17}$ These primary afferents (mainly C-fibers and A $\delta$-fibers) are implicated in the sensation of a variety of noxious painful stimuli. Block of high voltage-gated N-type calcium channel currents dramatically inhibits the release of neuropeptides as substance $\mathrm{P}$ and calcitonin generated peptides from sensory neurons. ${ }^{18}$

In our study the postoperative VAS pain scores were lower in group 2 and group 3 as compared to the control group at $1^{\text {st }}, 2^{\text {nd }}, 3^{\text {rd }}, 5^{\text {th }}, 6^{\text {th }}, 8^{\text {th }}, 10^{\text {th }}, 15^{\text {th }}$ and $18^{\text {th }}$ hour $(\mathrm{P}=0.002)$ however there was significant difference at $1^{\text {st }}$ and $2^{\text {nd }}$ hour in intrathecal vs intravenous group. Our results are in accordance with study by Samir et al. ${ }^{14}$ The VAS score was significant at $1^{\text {st }}$, and $2^{\text {nd }}, 6^{\text {th }}, 12^{\text {th }}$ and $24^{\text {th }}$ hour similar to our study. The VAS Score was significantly less in intravenous and intrathecal group as compared to control group, but there was no statistical significance between these two groups.

All the patients were haemodynamically stable intraoperatively in all three groups and no intervention was required.

Our data showed that the patients who received intravenous magnesium sulphate had maximum pain free interval, lower pain scores, longer sensory and motor blockade and less requirement of rescue analgesia as compared to the patients in intrathecal group or control group. All the patients were comfortable in the postoperative period. Thus we concluded that magnesium sulphate prolongs the postoperative analgesia with minimum side effects when given through either intravenous or intrathecal route.

The study has few limitations such as we did not measure the serum and CSF $\mathrm{Mg}^{++}$levels preoperatively and in postoperative period due to some technical reasons. The measurement of the $\mathrm{Mg}^{++}$levels could have helped us in better correlation of serum magnesium concentration with the pain free period in intravenous group and also we could have ascertained any correlation between the CSF $\mathrm{Mg}^{2+}$ levels and the analgesic effects in the intrathecal group the measurement of serum magnesium concentration after study drug administration was not done, which could have been more informative. Therefore further studies are required in this regard.

\section{CONCLUSION}

Thus we concluded that magnesium sulphate prolongs the postoperative analgesia with minimum side effects when given through either intravenous or intrathecal route.
However intravenous magnesium sulphate was more effective as compared to intrathecal route with regards to the pain scores and in providing postoperative analgesia.

Funding: No funding sources

Conflict of interest: None declared

Ethical approval: The study was approved by the Institutional Ethics Committee

\section{REFERENCES}

1. Kara H, Sahin N, Ulusan V, Aydogdu T. Magnesium infusion reduces perioperative pain. Eur $\mathrm{J}$ Anaesthesiol 2002;19:52-6.

2. Tramer MR, Schneider J, Marti RA, Rifat K. Role of magnesium sulphate in postoperative analgesia.Anesthesiology. 1996;84:340-7.

3. Woolf CJ, Thompson WN. The induction and maintenance of central sensitization is dependent on N-methyl-d-aspartate acid receptor activation: Implications for the treatment of post-injury pain hypersensitivity states. Pain. 1991;44:293-9.

4. Ryu JH, Kang MH, Park KS, Do SH. Effects of magnesium sulphate on intraoperative anaesthetic requirements and postoperative analgesia in gynaecology patients receiving total intravenous anaesthesia. Br J Anaesth. 2008;100:397-403.

5. Apan A, Buyukkocak U, Ozcan S, Sari E, Basar H. Postoperative magnesium sulphate infusion reduces analgesic requirements in spinal anaesthesia. EurAnaesthesiol. 2004;21:766-9.

6. Unlugenc H, Ozalevli M, Gunduz M, Gunasti S, Urunsak IF, Guler T et al. Comparison of intrathecal magnesium, fentanyl, or placebo combined with bupivacaine $0.5 \%$ for parturients undergoing elective caesarean delivery. Acta Anaesthesiol Scand. 2009;53:346-53.

7. Haubold HA, Meltzer SJ. Spinal anaesthesia by magnesium sulphate. J Am Med Assoc. 1906;46:64750.

8. Kroin JS, McCarthy RJ, Von Roenn N, Schwab B, Tuman KJ, Ivankovich AD. Magnesium sulphate potentiates morphine antinociception at the spinal level. Anesth Analg. 2000;90:913-7.

9. Fox C, Ramsoomair D, Carter C. Magnesium: Its proven and potential clinical significance. Southern Medical Journal. 2001;94(12). Available at: http://www.medscape.com/ view article / 423568

10. Kiran S. Gupta R, Verma D. Evaluation of a singledose of intravenous magnesium sulphate for prevention of postoperative pain after inguinal surgery: Indian J Anaesth. 2011;55:31-5.

11. Albrecht E, Kirkham KR, Liu SS, Bruli R. Perioperative intravenous administration of magnesium sulphate and postoperative pain: A metaanalysis.Anaesth $\mathbf{J}$ Assoc Great Britain and Ireland. 2013;68:79-90.

12. Buvanendran A, McCarthy RJ, Kroin JS, Leong W, Perry P, Tuman KJ. Intrathecal magnesium prolongs 
fentanyl analgesia: A prospective, randomized, controlled trial. Anesth Analg. 2002;95:661-6.

13. Elshanouby NM, Eid HE, Nahla F, Moharram AN. Intra-articular injection of magnesium sulphate and or Bupivacaine for post-operative analgesia after Arthroscopic knee surgery: Anesth and Analg. 2008;106:1548-52.

14. Samir EM, Badawy SS, Hassan AR. Intrathecal vs intravenous magnesium as an adjuvant to bupivacaine spinal anesthesia for total hip arthroplasty. Egyptian Journal of Anaesthesia. 2013;29(4):395-400.

15. Kumar M, Dayal N, Rautela RS, Sethi AK. Effect of intravenous magnesium sulphate on post- operative pain following spinal anesthesia. A randomized double blind controlled study. M.E.J. Anesth. 2013;22:251-6.

16. Gohil K, Bell JR, Ramachandran J, Miljanich GP. Neuroanatomical distribution of receptor for a novel voltage-sensitive calcium channel antagonist.SNX-

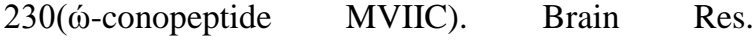
1994;653:258-66.

17. Vanegas H, Schaible HG. Effects of antagonists to high threshold $\mathrm{Ca}$ channels upon spinal mechanism of pain, hyperalgesia and allodynia. Pain. 2000;85:918.

18. Banihashem N, Hasannasab B, Esmaeili A, Hasannasab B. Addition of intrathecal magnesium sulphate to bupivacaine for spinal anesthesia in cesarean section. Anesth Pain Med. 2015;5:1-4.

Cite this article as: Kumar A, Chaudhary UK, Kansal D, Rana S, Sharma V, Kumar P. Comparison of intravenous Magnesium Sulphate with intrathecal Magnesium Sulphate for post- operative analgesia in orthopaedic patients undergoing extracapsular hip fracture surgery. Int J Basic Clin Pharmacol 2017;6:159-66. 